\title{
Sobre la imaginación productiva en la Crítica de la Razón Pura
}

\section{On the productive imagination in the Critique of Pure Reason \\ Sobre a imaginação produtiva na Crítica da Razão Pura}

Diego Sanhueza ${ }^{1}$

Recibido: 11/11/16 - Aceptado: 02/12/16

\begin{abstract}
Resumen:
En este escrito se analizan los elementos de una teoría de la imaginación en la Crítica de la Razón Pura de Kant. La gran novedad del tratamiento que Kant le da a la imaginación consiste en postular la existencia de una imaginación productiva, es decir, una imaginación que es anterior y que está en la base de la imaginación empírica. En este artículo, se realiza este análisis en dos pasos: en primer lugar, se examina el significado de la noción de "imaginación", distinguiéndola de las otras facultades (sensibilidad y entendimiento); en segundo lugar, se distinguen dos niveles en la imaginación misma, uno reproductivo y otro productivo.
\end{abstract}

Palabras Clave: Imaginación - Síntesis - Producción - Percepción - Concepto

\begin{abstract}
:
In this paper, the elements of a theory of imagination are analyzed in Kant's Critique of Pure Reason. The great innovation of Kant's treatment of imagination consists in proposing the existence of a productive imagination, that is, an imagination which is prior and is at the basis of the empirical imagination. This article carries out the analysis in two steps: firstly, it reviews the meaning of the notion of "imagination", distinguishing it from the other faculties (sensitivity and understanding); secondly, two levels are distinguished in the imagination itself, one reproductive and another productive.
\end{abstract}

Keywords: Imagination - synthesis - production - perception - concept

1 Doctor en filosofía. Contacto pielago123@gmail.com 


\begin{abstract}
Resumo:
Neste escrito, analisam-se os elementos de uma teoria da imaginação na Crítica da Razão Pura de Kant. A grande novidade do tratamento que Kant dá a imaginação é postular a existência de uma imaginação produtiva, ou seja, uma imaginação que é anterior e se encontra na base da imaginação empírica. Neste artigo, se realiza esta análise em duas etapas: em primeiro lugar, examina-se o significado do conceito de "imaginação", distinguindo-a de outras faculdades (sensibilidade e entendimento); em segundo lugar, se distinguem dois níveis na imaginação mesma, um reprodutivo e outro produtivo.
\end{abstract}

Palavras-chave: Imaginação - síntese - produção - percepção - conceito.

\title{
Introducción
}

En este escrito, intentaré reconstruir los elementos básicos de una teoría de la imaginación en la Crítica de la Razón Pura (1781). Su importancia y novedad fue reconocida rápidamente por los idealistas alemanes y posteriormente por Heidegger. La nota distintiva de este tratamiento es que Kant le asigna a la imaginación un estatuto a priori, estatuto insólito en la tradición filosófica. La idea, pues, de una imaginación productiva fue lo que movilizó todo el interés en ella. El objetivo de este artículo consiste entonces en delimitar lo más claramente posible el significado general de la imaginación y de su nuevo estatuto. Para ello, se examinará primero el concepto general de imaginación (cap.1-5), luego se revisarán dos tipos de imaginación (cap. 6) y finalmente se analizará el adjetivo productivo/a. Todo, por supuesto, dentro del marco general de la Crítica de la Razón Pura².

2 Citamos según Crítica de la Razón Pura, Ciudad de México, Fondo de Cultura Económica, 2010. Traducción, introducción y notas de M. Caimi. Los números entre paréntesis corresponden a la edición de la Academia. 


\section{Síntesis}

Tal y como su nombre lo indica, la imaginación (Einbildungskraft) es la facultad de las imágenes (tanto en español como alemán). En un texto en que responde algunas objeciones planteadas por el racionalista Eberhard, Kant define imagen de la siguiente manera: imagen es "una intuición que contiene en sí una multiplicidad en ciertas relaciones, por consiguiente, [contiene en sí] una figura (Gestalt). ${ }^{\prime 3}$ En el capítulo que sigue seré más específico con esta definición. Por ahora lo importante es lo siguiente: la imagen es una representación intuitiva que está en "ciertas relaciones". ¿De qué relaciones se trata? Según la cita, estas relaciones permiten que la multiplicidad tenga una figura o una forma, es decir, sea algo determinado (un perro, una casa, un árbol). Estas relaciones de las que habla Kant, entonces, dotan a la multiplicidad de unidad. De esto se desprende que la imaginación es aquella facultad que produce este cambio cualitativo en la multiplicidad: ella "tiene que llevar lo múltiple de la sensibilidad a una imagen" (A120). La imaginación se define en consecuencia por una acción, una que técnicamente se denomina "síntesis". La síntesis, por oposición al análisis, es una acción que "añade unas a otras diversas representaciones" (A77/B103), generando unidad. Que la imaginación sea facultad de síntesis constituye la definición básica de esta facultad en la Crítica de la Razón Pura.

\section{Imagen}

Cabe ahora preguntarse por el tipo de "unidad" que la imaginación produce. ¿Qué tipo de unidad es la imagen? En un sentido muy general, la imagen es unidad de una multiplicidad específica, unidad de lo que no está presente. Es lo que conocemos comúnmente como una "imagen mental". La imaginación crea esta imagen con total libertad y puede hacerlo porque no depende de la presencia inmediata del objeto

3 La polémica sobre la Razón Pura (respuesta a Eberhard), Madrid, Antonio Machado Libros, 2002. Edición y traducción de M. Caimi, p. 104. 
(como la sensibilidad). Por ejemplo: estoy en mi habitación y, mientras los sentidos reciben necesariamente la información de los objetos que me rodean (un escritorio, por ejemplo), la imaginación puede imaginar lo que quiera: un león. Kant se refiere a esta definición de imaginación en la "Deducción trascendental B" 4: la imaginación es "facultad de representar en la intuición un objeto aun sin la presencia de él" (B151).

Pero hay otro concepto de imagen. En una nota a pie de página de la "Tercera sección" de la "Deducción Trascendental A", Kant señala que la imaginación tiene también un rendimiento perceptivo. Esto, comenta el filósofo alemán, ha sido desatendido por los sicólogos y ello por la siguiente razón: "Se creyó que los sentidos no solamente nos suministraban impresiones, sino que además las combinaban y producían imágenes de los objetos" (A120). Se creía que los sentidos sintetizaban el dato sensible, produciendo una imagen del objeto percibido; pero, arguye Kant, no es posible que los sentidos mismos realicen esta labor: es imposible que los dos ojos produzcan una sola imagen del objeto. Para ello se requiere la intervención de una facultad activa, la imaginación: ella es la única que puede sintetizar el material disperso. En este contexto, imagen ya no significa "presencia del objeto ausente" (imagen mental), sino "aspecto del objeto presente". Si nos remitimos al ejemplo del párrafo anterior, entonces esta imagen ya no corresponde al "león que está en mi mente", sino al "escritorio que está frente a mí".

Los dos conceptos de imagen son muy distintos: el primero apunta a la presencia de lo que no está presente, mientras que el segundo apunta a la presencia de lo que está presente. De todas maneras, el significado básico de imaginación como síntesis se mantiene, sólo que en un caso lo sintetizado es una multiplicidad no actual, mientras que, en el segundo, es una multiplicidad actual ${ }^{5}$.

4 Como se sabe, la Crítica de la Razón Pura tiene dos ediciones (1781 y 1787) y la sección que se denomina "Deducción trascendental de las categorías" presenta importantes diferencias en una y otra. Para referirnos a la primera edición, hablaremos simplemente de Deducción A; para referirnos a la segunda, de Deducción B.

5 Strawson (1974) ha desarrollado un argumento en que la imaginación como pro- 
En términos de sentido común, se suele restringir el rendimiento de la imaginación al primer dominio, atribuyéndole exclusivamente a la sensibilidad el contacto directo con lo presente. Gran parte del argumento kantiano consistirá, sin embargo, en demostrar que esa suposición es incorrecta y que esa presencia que pensamos inmediata (el objeto percibido) en realidad está mediada por la síntesis de la imaginación.

\section{Concepto}

La imaginación es facultad de síntesis. Ella reúne el material sensible, unificándolo. El producto de esta labor se denomina imagen, y esta debe ser entendida no tanto en su acepción de "imagen mental" (león), sino en la de "aspecto del objeto percibido" (escritorio). Todo ello sirve para distinguir claramente la función activa de la imaginación de la meramente pasiva de la sensibilidad.

Sin embargo, la imaginación no puede realizar su labor por sí sola. Kant insiste en que ella es una "función ciega" (A78/B103), es decir, carente de concepto. La imaginación junta, pero no sabe cómo. El modo en que ella debe ejecutar su acción le viene prescrito de otro lado: del concepto. Sin la intervención de este, la imaginación sólo crearía una "muchedumbre de fenómenos" (A111) o un "amontonamiento carente de reglas" (A121). Esta subordinación de la imagen al concepto es tal, que Kant incluso afirma que ellas (las imágenes) "siempre presuponen un concepto del cual son la exhibición" (2002, 205).

Resumiré lo que he dicho sirviéndome libremente de la teoría de las cuatro causas atribuida al Estagirita. Entonces, en la teoría de la imaginación encontramos: a) una causa material, un material determinable:

ductora de la "imagen mental" y como productora del "aspecto del objeto percibido" coinciden. La clave consiste en atender el índice de no-actualidad, que es evidente en la "imagen mental" (pues ella no es sino una no-actualidad hecha presente) y que es menos evidente en el "objeto percibido". Para reparar en la no-actualidad que es constitutiva del objeto percibido, véase los análisis que le dedicamos a la triple síntesis, especialmente la sección referida a la reproducción. 
la intuición sensible dispersa; b) una causa formal o patrón de determinación: el concepto; c) una causa eficiente, una acción determinante: la síntesis de la imaginación; d) finalmente, una causa final: la unidad sintética, es decir: ni unidad conceptual vacía ni materia sensible dispersa.

\section{Triple síntesis}

El modelo que he reconstruido en la sección anterior se ve fielmente reflejado en lo que Kant denomina una teoría de la "triple síntesis". Se trata de un análisis que sólo aparece en la Deducción A, pero, dado que es muy ilustrativo y que su vocabulario se mantiene en la Deducción B, resulta provechoso repasarlo.

Antes de abordar el detalle, sin embargo, es preciso señalar que no estamos en presencia de tres síntesis distintas, sino de una y la misma síntesis, una cuyo proceso general puede ser dividido en tres momentos: aprehensión, reproducción y recognición. Como el lector lo podrá notar, estos tres momentos coinciden con tres dimensiones del modelo productivo: la aprehensión está directamente relacionada con lo sensible, la recognición con el concepto, mientras que la reproducción es, si se puede decir así, lo propiamente sintético de la imaginación.

Revisemos ahora cada uno de los momentos de la síntesis con más detalle.

\section{A) Aprehensión}

Kant define de la siguiente manera la aprehensión: ella es la acción de "recorrer la multiplicidad y luego reunirla" (A99). Como se ve, la aprehensión está directamente vinculada con lo múltiple de la sensibilidad: ella es una "acción ejercida inmediatamente sobre las percepciones" (A120). Kant no es totalmente explícito en este punto, pero creo que esta multiplicidad puede ser entendida de dos maneras: como partes que conforman al todo-objeto (sincronía podríamos decir) o como sucesión de representaciones del mismo todo-objeto (diacronía podríamos decir). Si usamos el ejemplo de una casa, entonces en el primer caso se 
trataría del techo, las ventanas, el piso: todos aquellos elementos que podemos ver en un instante (sincronía). En el segundo caso, se trataría de las distintas imágenes sucesivas que tengo de la misma casa: mi casa ahora, hace una hora, ayer, hace diez años, etc. (diacronía). Ahora bien, tal y como ha indicado Hoppe $(1983,183)$, este segundo tipo de ejemplos (el que involucra sucesión y diacronía) es probablemente más adecuado para los objetivos de Kant. Y ello porque aquí el tiempo juega un rol preponderante: lo que se tiene que enlazar son las sucesivas impresiones que una cosa va "dejando" en nuestra sensibilidad. ¿Cómo se recuperan esas impresiones que van quedando "atrás"? Según Kant, por medio del segundo momento de la síntesis, la reproducción.

\section{B) Reproducción}

Así define Kant la ley de la reproducción:

"Las representaciones que con frecuencia se han sucedido o acompañado, terminan por asociarse unas con otras, y con ello se ponen en una conexión según la cual, aun sin la presencia del objeto (ohne die Gegenwart des Gegenstandes), una de esas representaciones produce un tránsito de la mente a la otra, según una regla constante" (A100)

Como se puede apreciar, estamos en presencia de la ley de la asociación y la influencia de Hume es aquí manifiesta. Sin embargo, a Kant no le interesa tanto destacar el hecho de que la asociación actual tiene un origen relativamente arbitrario (una asociación empírica del pasado), sino el hecho de que, en el presente, se produce este "tránsito" en la mente de una representación a otra: la representación actual está asociada con otras representaciones no-actuales (esas que van quedando "atrás"). Pues bien, esta asociación se cumple de manera reproductiva: las representaciones no-actuales son re-producidas en el presente. Gracias a esto, el objeto presente se transforma en una "representación completa" (A102). Kant utiliza el ejemplo de la línea:

"Es menester que si trazo, en el pensamiento, una línea (...) debo primero, necesariamente, asir en el pensamiento, 
una tras otra, múltiples representaciones. Pero si yo dejara que se me fuera del pensamiento la representación precedente (las primeras partes de la línea) y no las reprodujera al pasar a las siguientes, entonces nunca podría surgir una representación completa" (A102).

Cabe precisar que esta re-producción del pasado no ocurre al modo del recuerdo. Strawson pone el ejemplo de un rostro que no conocemos y de un rostro que conocemos. Del primero no sabemos nada, es primera vez que lo vemos; el segundo lo conocemos, es decir, está asociado con algunas impresiones no-actuales, aunque ello no significa -este es el punto- que recordemos alguna anécdota precisa con esa persona. "Las representaciones pasadas están vivas en la presente percepción", señala el filósofo inglés $(1974,53)$. Por ello el vocabulario ligado a la "reproducción" es, en mi opinión, relativamente problemático: conduce con mucha facilidad a la noción de recuerdo. Me parece buena la paráfrasis de Wunsch: él habla de una síntesis de "retención en el presente" $(2007,148)$.

Es necesario que la reproducción se ejecute. $Y$ es necesario porque, de otro modo, la aprehensión estaría sometida a una suerte de flujo heracliteano: la representación nueva emergería siempre sin antecedentes y nos sorprendería cada vez (cfr. los conocidos ejemplos de Kant sobre el cinabrio, A100). Pero la reproducción sola aún no es capaz de producir unidad. Aquí debemos recordar aquello que dijimos sobre la imaginación, eso de que ella es función ciega. Es decir, ella reproduce, pero no sabe cómo. Podría darse el caso de que ella reprodujera caóticamente el pasado y sólo creara "amontonamientos carentes de regla". Es imprescindible, entonces, no sólo que la reproducción se ejecute, sino que se ejecute con orden. $Y$ ese orden, lo sabemos, viene del concepto.

\section{C) Recognición}

La recognición es el procedimiento mediante el cual la reproducción se realiza con orden. Escribe Kant: "La reproducción de ellas [las representaciones] debe tener una regla según la cual una representación debe 
ponerse en conexión más bien con esta que con otra en la imaginación" (A121). Esta regla enlaza lo múltiple de una determinada manera, es una suerte de instrucción que la imaginación debe seguir para crear unidad. Merced al re-conocimiento, entonces, volvemos a conocer al presente como parte del pasado, conectamos una y otra dimensión identificándolas y, así, producimos una percepción completa y estable: lo nuevo no es absolutamente nuevo, sino lo mismo que estaba antes.

Por supuesto, esta "regla" ya no pertenece al dominio estricto de la imaginación, sino al del entendimiento o, en última instancia, a la apercepción. Esta garantiza que todo el proceso se lleve a cabo según un orden predispuesto y que el resultado sea el esperado: unidad de la imagen, es decir, imagen sin más.

\section{Definición}

Me parece que ya tenemos los elementos suficientes como para dar una definición relativamente satisfactoria de imaginación y cumplir así nuestro primer objetivo. En función de lo dicho, podríamos decir que la imaginación es una facultad espontánea no inteligente. Que sea facultad quiere decir que ella tiene asignada una función propia, ella es capaz de hacer algo que ninguna otra facultad puede. Que sea espontaneidad la aleja de toda sensibilidad, de toda pasividad y receptividad. Por último, que ella sea no-inteligente significa que su espontaneidad no es la del concepto. Por eso -por esa falta- ella sigue siendo sensible. Pero no al punto de ser pasiva, es decir, receptiva. Como vieron Fichte y Heidegger, el estatuto de la imaginación es esencialmente "oscilante": ella no es ni sensible ni intelectual, o es en parte sensible (por ciega) y en parte intelectual (por espontánea) ${ }^{6}$. Kant afirma esta ambivalencia en numerosas oportunidades. Por ejemplo:

6 En su Doctrina de la ciencia (1794), Fichte caracteriza a la imaginación de la siguiente manera: "Imaginación es una facultad que oscila (schwebt) en el punto medio que hay entre la determinación y la no-determinación, entre lo finito y lo infinito" (1965, 360). En su Kant-Buch (1929), por su parte, Heidegger refiere el "extraño carácter irisado" (merkwürdig schillernden Charakter) de la imaginación (1991, 129). 


\begin{abstract}
"Ahora bien, como toda nuestra intuición es sensible, la imaginación, en virtud de la condición subjetiva sólo bajo la cual ella puede darles a los conceptos del entendimiento una intuición correspondiente, pertenece a la sensibilidad; pero en la medida en que la síntesis de ella, empero, es un ejercicio de la espontaneidad, (...) en esa medida la imaginación es una facultad de determinar a priori a la sensibilidad y su síntesis de las intuiciones, de acuerdo con las categorías, debe ser la síntesis trascendental de la imaginación." (B151-152).
\end{abstract}

La ambigüedad estructural de la imaginación ha generado muchas dificultades en el examen de su estatuto. Pese a ello, es menester subrayar que precisamente en virtud de esa ambigüedad la imaginación puede desempeñar el rol que Kant le encomienda: mediar entre la sensibilidad y el entendimiento. Sin esta mediación, tanto la sensibilidad como el entendimiento quedarían como compartimentos estancos: la primera condenada a la dispersión y el segundo, a la mera formalidad vacía. El rol mediador de la imaginación es tan importante que Kant no duda en señalar que la síntesis "es el motivo por el cual, propiamente, la crítica entera existe" (A14/B28).

\title{
6. Imaginación productiva y reproductiva
}

En relación con las facultades, Kant realiza dos operaciones fundamentales. En primer lugar, distingue entre facultades. Esta distinción toma generalmente el siguiente aspecto: existen cuatro facultades, la sensibilidad, la imaginación, el entendimiento y la apercepción. Cuando Kant afirma que la imaginación es una "función ciega" (espontaneidad no inteligente), la está distinguiendo de las otras facultades. Eso fue lo que acabamos de ver en los apartados anteriores. Con ello ya hemos determinado los rasgos más generales de la imaginación en la Crítica de la Razón Pura.

En segundo lugar, Kant distingue dos dimensiones en las facultades: una empírica y una pura. En el caso específico de la imaginación, 
el filósofo alemán va a distinguir entre una dimensión reproductiva y una productiva. No hay que confundir la primera de ellas con el momento reproductivo de toda síntesis que vimos en el análisis de la triple síntesis. En efecto, la dimensión empírica (reproductiva) de la imaginación estará a su vez constituida por los tres momentos (aprehensión, reproducción, recognición); por su parte, la dimensión pura o productiva tendrá también un momento reproductivo. Sea como sea, aquí lo relevante es que al fin aparece el adjetivo que nos interesa. Desentrañar lo propiamente "productivo" de la imaginación será pues el objetivo principal de este apartado y con ello habremos terminado nuestra tarea.

Veamos ahora con un poco más de detalle las dos dimensiones de la imaginación. Partamos por la reproductiva.

\subsection{La dimensión reproductiva de la imaginación}

La imaginación reproductiva liga representaciones según las asociaciones que se han producido empíricamente en el pasado: re-produce pues lo que la experiencia le enseña. ¿No es entonces un concepto el que guía la síntesis de la imaginación? ¿Ha fracasado nuestro modelo? No. Lo que pasa es que a partir de la experiencia se forman conceptos empíricos y éstos sirven retroactivamente para determinar la experiencia. Por ejemplo: gracias a la experiencia hemos llegado a saber lo que es un "perro". Luego, gracias a este concepto empírico, somos capaces de identificar ejemplares muy distintos bajo el universal "perro": grandes, chicos, de color café, cobrizo, blanco, etc. Por esta misma razón, y atendiendo a una dificultad que Hoppe ha identificado $(1983,186)$, hay que señalar que la síntesis de la reproducción no sólo opera según conceptos, sino que más bien conduce a ellos. En efecto, no existen los conceptos empíricos a priori y todos ellos han sido generados mediante un proceso abierto o elástico (Hoppe 1983,186 , nota 13). De no ser así, o bien no tendríamos concepto empírico alguno o bien contaríamos con un repertorio cerrado de conceptos empíricos, de modo tal que sólo podríamos conocer lo que ya conocemos. 
Si nos remitimos al modelo productivo que esbozamos en el capítulo 4, aquí tenemos: a) un material determinable, uno que técnicamente se denomina sensación o impresión y que está directamente relacionado con los sentidos; b) una imaginación reproductiva, que asocia c) según la experiencia o los conceptos que surgen de ella. El resultado es d) una imagen empírica. Se trata de una unidad sintética que, sin embargo, carece absolutamente de necesidad. La causa de esto es sencilla: nada impide que lo que ha estado asociado en el pasado deje de estarlo o que lo que no ha estado asociado en el pasado pueda estarlo. Nada impide que nuestro concepto empírico de "perro" se modifique según nos lo muestre la experiencia. Para encontrar necesidad tendremos que pasar al nivel productivo de la imaginación.

\subsection{La dimensión productiva de la imaginación}

La imaginación productiva es una de las grandes innovaciones de la teoría crítica kantiana. Su aparición tiene lugar en la "Deducción trascendental de las categorías". Allí podemos leer:

"La imaginación es, pues, también una facultad de una
síntesis a priori, y por eso le damos el nombre de una
imaginación productiva, y, en la medida que no tiene, con
respecto a todo el múltiple del fenómeno, otra intención
que la unidad necesaria en la síntesis de este, esta puede
llamarse la función trascendental de la imaginación" (A123.
Cfr. B152)

¿Qué debemos entender entonces por esta imaginación productiva? Si es productiva, ¿qué produce? Ya sabemos que la imaginación produce imágenes. ¿De qué imágenes se trata en este caso?

Puede resultar útil servirnos nuevamente de nuestro modelo productivo. Entonces: a) hay que procurarse un material determinable. ¿Qué material es este? Ya no se trata de la sensación, porque esta siempre es a posteriori. Hay que encontrar un material que sea a priori. ¿Una sensibilidad a priori? Eso suena como un contrasentido, pero es precisamente lo que Kant ha tematizado en la sección denominada estética 
trascendental. Kant se refiere a este misterioso material en algunos pasajes. Por ejemplo:

"La lógica trascendental tiene a priori ante sí un múltiple de la sensibilidad, que la estética trascendental le ofrece, para darles a los conceptos puros del entendimiento una materia sin la cual ella no tendría ningún contenido y por tanto sería enteramente vacía." (A77/B102).

Ya tenemos un material a priori. b) También sabemos que la acción que determina este material a priori es la síntesis trascendental de la imaginación productiva. A su vez, c) sabemos que esta actividad, por sensible, se tiene que guiar por el patrón de determinación conceptual. En este caso, se trata de las categorías kantianas. Ellas son conceptos puros, no se heredan de la experiencia y constituyen, por decirlo así, el patrimonio a priori del sujeto. Por esta misma razón, la síntesis productiva siempre tiene un patrón de determinación por el cual se puede guiar; no se trata de un proceso abierto o elástico, entonces, como en el caso de la síntesis reproductiva ${ }^{7}$.

Por último, el producto sintético del proceso productivo d) es una "imagen pura". La expresión "imagen pura" puede parecer antojadiza y arbitraria, pues el mismo Kant, en el capítulo dedicado al esquematismo, niega que las categorías puedan producir imágenes: "El esquema de un concepto puro del entendimiento es algo que no puede ser llevado a imagen alguna" (A142/B181). Pero hay otros pasajes en que el filósofo alemán acepta esta posibilidad. Por ejemplo, habla abiertamente de una "imagen pura" del espacio (A142/B182).

7 De todas maneras, la categoría es una representación a priori que necesita ser adquirida. Esta curiosa doctrina es mencionada en el texto La polémica sobre la razón pura (respuesta a Eberhard). Allí podemos leer: "La Crítica no admite en absoluto representaciones innatas; a todas ellas, ya pertenezcan a la intuición o a los conceptos, las considera adquiridas. Pero hay una adquisición originaria (...). Tal es, como lo afirma la Crítica, la unidad sintética de lo múltiple en los conceptos" (139). Para un desarrollo sistemático de esta idea, véase Oberhausen (1997). 
Además, cuestión quizá más importante, es coherente con toda su explicación de la imaginación ${ }^{8}$.

¿Qué es, pues, una imagen pura? Una explicación sobre este elusivo tipo de imagen sólo podría estar completa apelando a un análisis del esquematismo; pero esa explicación no es posible aquí. Remitámonos a lo más importante: así como la imaginación reproductiva, mediando entre la sensación y el concepto empírico, crea la "imagen empírica" del objeto, la imaginación pura, mediando entre lo múltiple a priori y la categoría, crea la "imagen pura" del tiempo y del espacio. ¿Qué relación hay entre ambas imágenes? La imagen pura establece las condiciones de posibilidad de la empírica: pone no el objeto empíricamente determinado (para este hay que esperar una sensación), sino las coordenadas espacio-temporales en las cuales este se inscribe. Estas condiciones universales y necesarias son lo que Kant denomina "objeto trascendental" o simplemente "objeto": "aquello que, en el fenómeno, contiene la condición de una regla necesaria de la aprehensión" (A191/B236)9.

El lenguaje que Kant utiliza en estos pasajes es sumamente abstracto y no se caracteriza precisamente por su claridad. Tal vez algunos ejemplos ayuden a clarificar este punto. Veamos qué pasa con las categorías de la cantidad (unidad, pluralidad y totalidad). En los Axiomas de la intuición, se parte con un ejemplo que ya conocemos, el de la línea. Anota Kant: "No puedo representarme línea alguna, por pequeña que sea, sin trazarla en el pensamiento; es decir, sin generar poco a poco todas las partes a partir de un punto y sin dibujar, ante todo, esta in-

8 Sin ir más lejos, Rosales ha reconstruido -exitosamente, a mi parecer- esta "teoría de la imagen" en relación con cada una de las categorías: "Hay que admitir que a cada esquema trascendental le corresponde su imagen pura" $(2009,256)$.

9 Este proceso -la producción de la imagen pura- es la exhibición de un concepto puro; es, por lo tanto, una "exhibición originaria" (según la expresión acuñada por Kant en el parágrafo 28 de su Antropología en sentido pragmático). Ahora bien, tenemos que distinguir esta exhibición originaria de la "construcción". Esta es un tipo específico de exhibición que sólo concierne a los conceptos sensibles puros (matemáticos). Anota el filósofo alemán: "Yo construyo un triángulo al exhibir el objeto que corresponde a ese concepto, ya mediante mera imaginación, en la intuición pura, ya en el papel, en la intuición empírica" (A713/B741). 
tuición de tal manera" (A163/B203). El trazado de la línea representa el paso cuantitativo de la unidad (el punto) hasta una representación completa o total (la línea). Y agrega Kant: "Lo mismo acontece con cualquier tiempo, aún el más pequeño. En él pienso solamente el tránsito sucesivo de un momento a otro, donde, a través de todas las partes del tiempo, y de su agregación, se genera finalmente una magnitud de tiempo determinada" (A163/B203). Es decir: mediante la imaginación productiva y el esquema de la cantidad (el número) los instantes se agregan y se produce una representación completa del tiempo: una duración específica, cuantitativamente determinada. Esta es lo que hemos denominado una "imagen pura" del tiempo, la cual, como condición de posibilidad, debe acompañar a todo objeto empírico.

La dimensión pura o trascendental de las facultades crea las condiciones de posibilidad del correcto desempeño de la dimensión empírica. Es el soporte de nuestra experiencia y permite que esta se despliegue con regularidad: si la imaginación empírica asocia (empíricamente) objetos, la productiva crea la posibilidad de estos. Se anticipa, pues, a todo fenómeno u objeto, prescribiéndole ciertas coordenadas básicas. En este sentido, son a priori y contienen necesidad.

\section{Diferencias entre la primera y la segunda edición}

Como se sabe, la Deducción A es significativamente distinta a la Deducción B. Una diferencia importante concierne al estatuto de la imaginación y por eso es importante que digamos algo aquí.

Expresado muy gruesamente, y remitiendo a los análisis de las páginas anteriores, ocurre que, de los dos grandes pasos argumentativos que se han dado, uno pierde fuerza en la Deducción B: el de la autonomía de la imaginación. El otro punto, aquel que dice relación con la identificación de dos niveles en las facultades, sigue intacto. Kant reconoce sin ambages en la Deducción B la existencia de una imaginación productiva: "En la medida en que la imaginación es espontaneidad, la llamo también a veces la imaginación productiva, y la distingo así de la reproductiva" (B152). Pero esta misma imaginación productiva 
ya no es independiente del entendimiento, ya no cumple una función que este por definición no puede cumplir. Ahora la imaginación es un caso del entendimiento: ella sólo es "el efecto del entendimiento sobre la sensibilidad" (B152). De hecho, como vimos en los apartados anteriores, la síntesis era (en la Deducción A) un patrimonio exclusivo de la imaginación, mientras que la Deducción B parte señalando que la síntesis "es una acción del entendimiento", la cual puede enlazar tanto la multiplicidad de elementos sensibles como la de varios conceptos (cfr. B130).

Este cambio de perspectiva también resulta evidente en una corrección que Kant hizo a su ejemplar impreso. En el parágrafo 10 (primera edición), se dice simplemente que la síntesis es "el mero efecto de la imaginación" (A78). Luego, aún en la primera edición, Kant agrega que esta facultad, pese a su ceguera, es "indispensable". Sin embargo, Kant agregó en su ejemplar ya impreso que esta facultad indispensable era "una función del entendimiento"10. Con ello el filósofo alemán suprime la autonomía de la imaginación, adosándole su función al entendimiento.

De todas maneras, y me parece importante recalcarlo, Kant tiene que discernir entre el plano ejecutivo (imaginación) y el plano formal (entendimiento). Y tiene que hacerlo porque su objetivo filosófico consiste precisamente en distinguir entre una unidad puramente formal y una unidad sintética. Por esta razón, la "síntesis pura del entendimiento" (B140) contendrá una diferencia interna. Por un lado, será síntesis intelectual "efectuada por el entendimiento sin imaginación alguna" (B152); por otro lado, será síntesis figurativa (B151) y entrará en contacto directo con el material sensible (parágrafo 24).

\section{Conclusión}

Antes de sacar algunas conclusiones, voy a resumir brevemente los pasos del argumento que aquí se ha desplegado. En el primer capítulo,

10 Nota 316 de la traducción que estoy utilizando. 
se ha visto que la imaginación era básicamente facultad de síntesis: acción que enlaza el material sensible. En el segundo capítulo, se ha visto que Kant distingue dos tipos de imágenes y que su interés radica en demostrar que la imaginación (síntesis) incide en la producción de la imagen entendida como "aspecto del objeto percibido". En el tercer capítulo, se ha señalado que la imaginación debe operar según conceptos para producir esta imagen. En el cuarto capítulo, se ha retomado el conjunto de estas caracterizaciones al reconstruir la teoría de la triple síntesis: aprehensión para el contacto directo con el material sensible, reproducción para el enlace de este material y recognición para la intervención del factor conceptual en la reproducción. En el quinto capítulo, y en función de todo lo que fue dicho, la imaginación fue definida como facultad espontánea no inteligente, completando así nuestro primer objetivo. En el capítulo sexto, se repasó la diferencia entre la dimensión reproductiva y la productiva, señalando que a la primera le corresponde la producción de la imagen entendida como aspecto del objeto empírico, mientras que a la segunda, la producción de la imagen pura. En el capítulo séptimo, se examinaron las diferencias entre la primera y la segunda edición, aclarando que el énfasis dado al entendimiento no impide que en él se distinga lo propio del entendimiento (síntesis intelectual) de lo propio de la imaginación (síntesis figurativa). Con ello se dio por finalizado el análisis.

Para concluir, diré que hay dos cuestiones novedosas en el tratamiento que Kant hace de la imaginación en la Crítica de la Razón Pura. De una parte, ella comienza a desempeñar un rol constitutivo en la percepción. De otra parte, este nuevo rol tiene un doble registro: uno empírico-reproductivo y uno puro-productivo, siendo este último el más importante y el más innovador. No en vano este nuevo registro de la imaginación llamó la atención de los idealistas alemanes y de los poetas románticos en general.

De todas maneras, a modo de glosa final, no podemos desconocer que el nuevo estatuto de la imaginación, pese a la inédita dignidad que recibe, sigue gravada por un déficit: ella, aun siendo productiva, es sensible: "En sí misma la síntesis de la imaginación, aunque ejercida a priori, es siempre sensible" (A124). Esto se traduce inmediatamente 
en una dependencia en relación con el entendimiento. En este sentido, no deja de ser problemático que la imaginación no pueda ser imaginación, es decir, no pueda producir imágenes, sin asistencia del concepto. De hecho, podríamos decir que, en el contexto de la Crítica de la Razón Pura, esta facultad se ve afectada por una disyunción intelectualista: la imaginación o bien produce según concepto, o bien es incapaz de producir con unidad. Por ello Longuenesse ha dicho que la imaginación está "apropiada" por el entendimiento en el contexto de la Crítica de la Razón Pura $(1998,207)$. Sin embargo, no debería sorprendernos que la medida para evaluar a la imaginación sea el conocimiento, pues la Crítica de la Razón Pura es un libro cuyo objetivo radica precisamente en analizar la posibilidad del conocimiento. Para encontrar desarrollos que hagan justicia a la autonomía de la imaginación habrá que esperar a la Crítica del Juicio. Recordemos que allí, siguiendo el hilo conductor de un análisis de lo bello, se habla explícitamente de un "libre juego de la imaginación" (parágrafo 9) y de una "esquematización sin concepto" (parágrafo 35).

\section{Bibliografía}

\section{Primaria}

Kant, I. Kants Werke. Akademie Textausgabe. Berlin, Walter de Gruyter, 1968 (-). Crítica de la Razón Pura, Ciudad de México, Fondo de Cultura Económica, 2010. Traducción, introducción y notas de M. Caimi. La polémica sobre la Razón Pura (respuesta a Eberhard), Madrid, Antonio Machado Libros, 2002. Edición y traducción de M. Caimi.

\section{Secundaria}

Aristóteles Acerca del alma, Madrid, Biblioteca Básica Gredos, 2002.

Fichte, J.G. Fichte-Gesamtausgabe, Werkeband 2, Bayerischen Akademie der Wissenschaften, München, 1965.

Heidegger, M. Kant und das Problem der Metaphysik, (GA3), V. Klostermann, Frankfurt am Main, 1991.

Hoppe, H. Synthesis bei Kant. Berlin, New York, W. de Gruyter, 1983. 
Longuenesse, B. Kant and the Capacity to Judge, Princeton, University Press, 1998.

Oberhausen, M. Das neue Apriori, Stuttgart, Frommann-Holzboog, 1997.

Rosales, A. Ser y subjetividad en Kant, Buenos Aires, Biblos, 2009.

Strawson, P Freedom and resentment, London, Butler \& Tanner, 1974.

Wunsch, M. Einbildungskraft und Erfahrung bei Kant, Berlin/New York, Walter de Gruyer, 2007. 